\title{
SAND DUNE VEGETATION SUCCESSION: CASE STUDY OF PANAMA VILLAGE IN EASTERN SRI LANKA
}

\author{
S.N. Wickiàmaratne1 \& H. I. Tillekaratne 2 . \\ 1Department of Geography, University of Peradeniya \\ 2Department 'of Botany, University of Peradeniya
}

Coastal sand dunes harbour special successional plant communities and are of immense ecological value. Henry Cowels, one of the pioneers to study ecological succession in the late $19^{\text {th }}$ century was inspired by the sand dunes of the shores of Lake Michigan.

In Sri Lanka coastal sand dunes occur along the dry zone coast. The stretch extending northward from Hambantota has a well-developed dune system in Panama in the Ampara District. The objective of the present study was to investigate the composition, structure and zonation of vegetation in the sand dune system of Panama between Kumbukkan Oya estuary and Arugam Bay. It was carried out in April 2002 by random plot sampling.

The dunes supporting the vegetation are more or less parallel to the shore and occur within $300 \mathrm{~m}$ from the shoreline (berm). They rise in four successive levels up to about $8 \mathrm{~m}$ from the berm level. The first three dunes are within $50 \mathrm{~m}$ from the berm, while the fourth one is between 150 and $300 \mathrm{~m}$ from the berm.

The vegetation shows a zonation in corformity with the successive dunes. The first zone $(0-7 \mathrm{~m}$ from berm) has creeping vegetation consisting of Spinifex littoreus etc. The second zone $(7-14 \mathrm{~m})$ has low herbs (e.g. Scaeovola sericea, Sesamum prostratum) in addition to creeping forms. These two zones together have 16 plant species. The third zone is a more stabilized terrain with 17 plant species exceeding $15 \mathrm{~cm}$ of height (Scaeovola, Crinum sp. and Calotropis gigantean etc.). The fourth zone is wider and more stabilized. It has about ten stunted tree species such as Crateva adansoni, Strychnos potatorum and Grewia carpinifolia.

The taller plants are swept in a southwest-northeast direction indicating the dominant wind direction.

Proceedings of the Eighth Annual Forestry and Environment Symposium 2002 of the Department of Forestry and Environmental Science. University of Sri Jayewardenepura, Sri Lanka 